\title{
EDITORIAL: TRANSCATHETER CLOSURE OF ATRIAL SEPTAL DEFECTS
}

Erle H. Austin, MD

$T_{\mathrm{in}}^{\mathrm{h}}$ e era of open heart surgery began with a variety of ingenious techniques directed at closure of the secundum atrial septal defect (ASD). ${ }^{1-4}$ Indeed, the first successful application of cardiopulmonary bypass was for this purpose. ${ }^{5}$ Direct vision intracardiac surgery owes its origins to the ASD. Over the past half century surgical closure of a secundum ASD has become a low-risk and highly successful procedure. ${ }^{6,7}$ In addition to being bread and butter for the heart surgeon, ASD closure has become a valuable procedure for introducing the cardiothoracic resident to true "open" heart surgery. Until recently, cardiovascular surgeons have felt privileged and (maybe, self-importantly) exclusively qualified to close these defects. Now our turf is being challenged once again by some bright and innovative nonsurgeons, the interventional cardiologists. Our cardiology colleagues, demonstrating ingenuity not unlike that of our predecessors in cardiac surgery, have developed techniques to close interatrial communications with a catheter! Is transcatheter ASD closure a safe and reasonable approach? Is it a threat to our livelihood or our ability to train residents? What role should we play in its introduction?

The first successful transcatheter closure of an ASD occurred a quarter of a century ago. Thus, it is somewhat surprising that the technique is only now becoming an alternative to surgery. The initial report in 1976 by King and Mills ${ }^{8}$ demonstrated the feasibility of the approach, but the requirement for a very large $(23 \mathrm{~F})$ delivery catheter precluded its application to the pediatric population. In the mid-1980s, based on a device initially designed by William Rashkind, ${ }^{9}$ James Lock and C.R. Bard, Inc (Murray Hill, NJ) applied the double-umbrella concept to develop the clamshell ASD occlusion device, ${ }^{10}$ which could be introduced through an $11 \mathrm{~F}$ femoral sheath. The Bard clamshell was introduced into a prospective nonrandomized multicenter Food and Drug

From the Division of Thoracic Surgery, Department of Surgery, University of Louisville, and Kosair Children's Hospital, Louisville, Ky.

Received for publication Sept 21, 2000; accepted for publication Oct 11, 2000.

Address for reprints: Erle H. Austin, MD, 201 Abraham Flexner Way, \#1200, Louisville, KY 40202.

J Thorac Cardiovasc Surg 2000;120;1032-3

Copyright @ 2000 by The American Association for Thoracic Surgery $0022-5223 / 2000 \$ 12.00+0 \quad \mathbf{1 2 / 1 / 1 1 2 0 8 7}$

doi: $10.1067 / \mathrm{mtc} .2000 .112087$
Administration (FDA) Investigational Device Exemption (IDE) clinical trial in 1989. ${ }^{11}$ More than 500 patients received the device. ASD closure was successful in the majority of patients with some procedure-related morbidity, no midterm morbidity, and no mortality. Success was most likely for central secundum defects less than 20 $\mathrm{mm}$ in diameter. As enthusiasm was building for the device, incidental breaks in the metal arms were noted. Although few, if any, serious sequelae developed from these breaks, it was clear that a material and design change was necessary and the device was withdrawn. Despite this design failure, this initial clinical experience indicated that many ASDs could be safely and effectively closed in the catheterization laboratory. Another ASD closure device, the Sideris buttoned occluder (Custom Medical Devices, Amarillo, Tex), has been implanted in more than 400 patients with similar results. ${ }^{12}$ At least three other ASD occluder devices (Das AngelWings device $^{13}$ [Microventa Corp, White-Bear Lake, Minn], ASDOS device ${ }^{14}$ [Osypka Corporation, Rheinfelden, Germany], and Amplatzer device ${ }^{15}$ [AGA Medical Corp, Golden Valley, Minn]) have been introduced and are being evaluated in clinical trials. Because of FDA restrictions, most of the experience with these newer devices has been obtained outside of the United States. In September of 1999, however, the FDA granted approval for the selective use of the latest generation of the clamshell device, the CardioSEAL Septal Occluder (Nitinol Medical Technology, Inc, Boston, Mass). Application of the device was limited to the closure of Fontan fenestrations and apical ventricular septal defects. In January of 2000 the closure of a patent foramen ovale for paradoxic embolization was added to the acceptable indications. It may not be long before the FDA adds small centrally located secundum ASDs to this list.

Thus, the writing is on the wall! Transcatheter closure is becoming an accepted technique for closure of patent foramen ovales and some ASDs. Because it can be performed without general anesthesia, without cardiopulmonary bypass, and without an incision, the technique must be considered an attractive alternative to conventional surgical closure. Although the cost of the device and the implantation facilities may be similar to those of surgical closure, hospitalization is shortened or eliminated and time off from work is greatly reduced. Let's admit it. Transcatheter ASD closure will be the best approach for some patients. 
Acceptance of the value of this technique, however, does not relieve the surgeon of an important role in its introduction into our local or regional cardiovascular programs. A close working relationship between the surgeon and the interventionalist will permit successful and safe application of this technique. The surgeon's role continues to be that of patient advocate, recognizing favorable and unfavorable anatomy, and participating in the selection of patients for the transcatheter approach. Ostium primum and sinus venosus ASDs, as well as large secundum defects with limited septal margins, are more suitable for closure under direct vision with cardiopulmonary bypass. Therefore, patients will continue to be available for the training of our residents. The other role the surgeon must play is that of backup in case of failure or device embolization. As always, the surgeon remains uniquely qualified for dealing with failures in the catheterization laboratory. The accompanying article by Berdat and associates ${ }^{16}$ describes the experience of a surgical team dealing with complications of transcatheter closure techniques.

The fact that complications have occurred with these techniques has not and should not dissuade its proponents from continuing to apply the devices. With any new technique a certain experiential learning curve is expected. In the present article $8 \%$ of patients required surgical intervention, an incidence that is likely to decrease with time. The average ASD diameter of $25 \mathrm{~mm}$ for patients coming to surgical intervention supports the concept that defect size is an important factor in selecting patients for device closure. Lessons learned from their experience are well described by the authors. The most common failure in their experience was malposition of the device resulting in a residual ASD, further evidence suggesting a problem with patient selection. The make of septal occluder may also be a factor, but comparative data in this regard are not yet available. More important, when surgery is required for a complication, conventional surgical techniques are successful with low morbidity. On the basis of the experience from Bern, it could be cogently argued that although surgery became necessary in some cases, transcatheter procedures saved more than $90 \%$ of patients from an open heart operation. The one death in the series, resulting from perforation of the left ventricle during percutaneous attempts to recover a dislocated device, should serve as an important warning that this new technique does have potential for mortality and must not be taken lightly. As transcatheter ASD closure is introduced into our medical communities, let us continue to foster a careful and deliberate collaboration between surgeon and interventionalist.

Finally, let us not forget that the ultimate success of any technique must be evaluated over the long term. A promising early result does not guarantee a favorable late outcome. Our own experience with the Ionescu-Shiley and convexo-concave Björk-Shiley valve prostheses attests to the importance of continued follow-up and critical evaluation for years to come. Surgical closure of an ASD has stood the test of time. Will the same be true for transcatheter closure?

\section{REFERENCES}

1. Bailey CP, Downing DF, Geckler GD, Likoff W, Goldberg, H, Scott JC, et al. Congenital interatrial communications: clinical and surgical considerations with a description of a new surgical technic: atrio-septo-pexy. Ann Intern Med 1952;37:888-920.

2. Gross RE, Pomeranz AA, Watkins E Jr, Goldsmith EI. Surgical closure of defects of the interauricular septum by the atrial well. N Engl J Med 1952;247:455-60.

3. Lewis FJ, Taufic M. Closure of atrial septal defects with the aid of hypothermia: experimental accomplishments and the report of one successful case. Surgery 1953;33:52-9.

4. Sondergaard T. Closure of atrial septal defects: report of three cases. Acta Chir Scand 1954;107:477-84.

5. Gibbon JH Jr. Application of a mechanical heart and lung apparatus to cardiac surgery. Minn Med 1954;37:171-80.

6. Horvath KA, Burke RP, Collins JJ Jr, Cohn LH. Surgical treatment of adult atrial septal defect: early and long-term results. J Am Coll Cardiol 1992;20:1156-9.

7. Pastorek JS, Allen HD, Davis JT. Current outcomes of surgical closure of secundum atrial septal defect. Am J Cardiol 1994;74:75-7.

8. King TD, Mills NL. Secundum atrial septal defects: nonoperative closure during cardiac catheterization. JAMA 1976;235:2506-9.

9. Latson LA. Transcatheter closure of atrial septal defects: In: Rao PS, editor. Transcatheter therapy in pediatric cardiology. New York: Wiley-Liss; 1993. p. 335-48.

10. Rome JJ, Keane JF, Perry SB, Spevak PH, Lock JE. Doubleumbrella closure of atrial defects: initial clinical applications. Circulation 1990;82:751-8.

11. Latson LA, Benson LN, Hellenbrand WE, Mullins CE, Lock JE. Transcatheter closure of ASD-early results of multi-center trial of the Bard clamshell septal occluder. Circulation 1991;84(Suppl):II-44.

12. Rao PS, Berger F, Rey C, Haddad J, Meier B, Walsh KP, et al. Results of transvenous occlusion of secundum atrial septal defects with the fourth generation buttoned device: comparison with first, second and third generation devices. J Am Coll Cardiol 2000;36:583-92.

13. Mendelsohn AM, Banerjee A, Schwartz DC, Das GS. Transcatheter atrial septal defect closure of Das Angel Wings transcatheter ASD occlusion device: the Cincinnati-Rochester experience. J Intervent Cardiol 1998;11:495-500.

14. Sievert H, Babic UU, Hausdorf G, Schneider M, Hopp HW, Pfeiffer D, et al. Transcatheter closure of atrial septal defect and patent foramen ovale with the ASDOS device (a multi-institutional European trial). Am J Cardiol 1998;82:1405-13.

15. Hijazi ZM, Cao Q, Patel H, Rhodes J. Transcatheter closure of atrial communications using the AmplatzerTM septal occluder. J Intervent Cardiol 1999;12:51-8.

16. Berdat PA, Chatterjee T, Pfammatter J-P, Windecker S, Meier B, Carrel T. Surgical management of complications after transcatheter closure of an atrial septal defect or patent foramen ovale. J Thorac Cardiovasc Surg 2000;120:1034-9. 